\title{
Assessing public open spaces in Belgrade - a quality of urban life perspective
}

\begin{tabular}{|r|l|}
\hline Journal: & Archnet-IJAR: International Journal of Architectural Research \\
\hline Manuscript ID & ARCH-04-2020-0064.R2 \\
\hline Manuscript Type: & Research Paper \\
\hline Keywords: & $\begin{array}{l}\text { Quality of urban life, Open public spaces, Urban space attributes, User } \\
\text { perception, Belgrade }\end{array}$ \\
\hline \multicolumn{2}{|l}{} \\
\hline
\end{tabular}




\title{
Assessing public open spaces in Belgrade - a quality of urban life perspective
}

\begin{abstract}
Purpose - This paper interrogates the impact of spatial transformations on urban life. It explores the level of individual and group satisfaction and sense of well-being within the urban public realm; this is undertaken by reporting on the outcomes of an assessment study of three key public open spaces in Belgrade, developed from a Quality of Urban Life (QoUL) perspective.
\end{abstract}

Design/methodology/approach - A systematic multi-level assessment method is utilized, with the aim of determining the material and immaterial elements that can contribute to an individual's sense of comfort within a public space. The study places emphasis on the functional, social and perceptual attributes as they relate to the physical characteristics of three assessed spaces.

Findings - The assessment study resulted in a systematic overview of the different attributes of the three assessed spaces. With various performance levels within each set of attributes, the study identifies key challenges and problems that could lead towards determining possible opportunities for future local urban interventions and developmental actions.

Originality/value - With the shifts in policies and the associated governance process that redefined the outlook of previously enforced development and urban growth in the last two decades, the capital of Serbia, Belgrade, has undergone significant spatial changes. This has resulted in a certain level of fragmentation in the urban fabric, leading to a number of challenges concerning public health, well-being, safety, accessibility, comfort, and urban mobility, to name a few, that need to be better addressed and understood within the local context.

Keywords Assessment, Quality of urban life, Open public spaces, Urban space attributes, User perception, Belgrade.

Paper type: Research paper

\section{Introduction}

The cities of Serbia have had a long turbulent history, with the urban scenery of its major cities continuously adapting to cultural, social and ideological changes. The dissolution and reestablishment of centralized city governing and managing systems in the country's recent past left imbalances in the urban landscapes, leaving cities permanently impacted by the dynamics of transition. This has resulted in an urban fabric which is becoming less adaptable. With new major changes future developmental strategies throughout the country and especially its capital, it has become imperative to understand how this imbalanced course of development has not only affected the spatial dimension of the urban environment, but also the well-being of the local communities. With the focus directed on the urban scale and the realm of open public spaces, this paper is centred on understanding how different spatial phenomena contribute to the overall quality of human life. On this basis, this work is to establish a mechanism towards assessing how the scenery of the urban environment reflects itself upon the liveability of a city; and how well-being and life satisfaction of citizens is mirrored upon it. 
Public open spaces play an important role in understanding the many different aspects of life within an urban environment, representing an urban resource that can be utilized to assess the economic, cultural, formal, functional or social dynamics of a city. With this understanding, this research aims to highlight the thread between spatial comfort within open public spaces and comfort with one's living conditions and satisfaction. Three open public spaces within the city of Belgrade were identified and analysed through a multi-level assessment method that enables identifying their qualitative characteristics that play a key role in shaping the way they are used, comprehended and acknowledged by their users.

\section{Quality of Urban Life}

With its diverse contextual background and recent multiple spatial shifts within its urban core, Belgrade, imposed itself as a good setting for contemporary research and analysis. The understanding and examination of urban environments through the Quality of (Urban) Life conceptual framework is identified as a pathway to reshape and transform human settlements into more liveable, socially sustainable and pleasant areas, in a way that would ensure their long-lasting growth and development (Rink et al., 2018). This conceptual framework can help reassess existing and emerging concerns in urban governance, planning, development, issues of sustainable growth, and the overall well-being of the urban population (Marans \& Stimson, 2011).

\subsection{Key Theoretical Tenets}

First emerging as a distinct conceptual framework in the 1970s, the topic of Quality of Life (QoL) is focussed on conceiving ways to adequately measure and quantify health and well-being of communities (MacLean \& Salama, 2019; McCrea et al., 2011; Romice et al., 2017). In order to determine the QoL on a smaller or wider scale, different methods have been proposed through the years, with the initial ones focusing primarily on the economic growth, status and prospects of individuals, cities, regions or countries (Eurostat, 2015; van Kamp et al., 2003; Theofilou, 2013). This paradigm shifted towards finding ways to not only assess the economic production, living standards, and basic and additional amenities which communities have access to, but also to determine people's individual satisfaction with a certain place and their overall happiness with the aspects that make up their everyday life (Marans \& Stimson, 2011; Pacione, 2003). Nevertheless, despite numerous research works delving into QoL, there seems to be no general consensus on a universal definition of the term (McCrea et al., 2011; van Kamp et al., 2003; Felce \& Perry, 1995). Thus, one of the most effective ways to assess QoL of the urban domain is through the contextual model approach which allows to simultaneously compare a wide array of diverse aspects of life.

The broad conceptual model of QoL incorporates a range of different life domains focusing on demographic, social, economic and environmental aspects identified as crucial for contributing to the overall life quality. The model provides a way to not only examine the objective indicators of QoL, but also underlines the importance of linking them with the level of human satisfaction with the different aspects of life, enabling an understanding of how people experience their surroundings through their interaction with it and how their subjective experience can differ from the objective reality. In this sense, according to Marans (2015), the concept of QoL is seen as a combination of the individual perception of inner and outer wellbeing, shaped and made out of subjective and objective aspects that shape an individual's life. Another important element of assessing QoL is the geographical scale on which we view various aspects, be it on the macro scale of a region or on a smaller scale of a neighbourhood or local community (McCrea et al., 2011; Pacione, 2003), where the human awareness of the urban scale provides individuals with an understanding of its sociospatial qualities. It is important to understand that people live in places and their overall experience and life satisfaction is shaped by the contextual environment they inhabit where the level of satisfaction can be increased or decreased through changes in any of the different spatial levels. This 
particularly important in contexts which have undergone rapid urban transformations (Wiedmann et al., 2013).

Determining the relation between the aspects of well-being of people within urban areas and their degree of satisfaction within it is usually defined as the assessment of the Quality of Urban Life (QoUL) (Marans, 2015), making up a subgroup of research connected to analysing the quality and liveability of cities and neighbourhoods. For the purpose of this research QoUL is defined as the way to develop and assure the conditions to manage cities and urban resources in a way that can impacts their ecological, biological, economic, social, cultural, typological, aesthetic and spatial elements (Páramo, 2017). In this sense, the value of an environment is seen as a product of interaction between these variables in a manner that addresses and satisfies the needs of a wide array of users.

When assessing a specific urban setting the use of sets of indicators is crucial for measuring conditions and qualities of place. There is a common agreement within the research community that both objective (based on the secondary assessment of official statistical datasets) and subjective (based on assessing human perception of different aspects of their life through primary data collection methods) indicators need to be used in order to adequately understand the level of human well-being (Stimson \& Marans, 2011). A standardized set of individual indicators has not yet been devised and generally accepted. There does however seem to be a noticeable overlap when defining the relevant domains for assessing QoL, with the five key ones being: physical wellbeing, material wellbeing, social wellbeing, emotional wellbeing, and development and activity (Felce \& Perry, 1995). All of these notions can be measured on the objective and subjective levels, while the level of overall human satisfaction is ultimately shaped by a system of individual personal values, which are in turn shaped by the historical, cultural, social and political context of the individuals using the environment under examination. These key domains of QoL have an implicit but direct connection to the physical features of an urban environment and the way people perceive it and by extent reflect on the aspects of life quality within a city. By and large, people feel satisfied with an urban space when their primary needs, ideally alongside their secondary needs, are met (Páramo, 2017).

\subsection{Quality of urban life indicators at the urban open space level}

The QoUL perspective for assessing urban space can be seen as seeking a way to understand the complex nature of the relationship between an individual and their built environment (Páramo, 2017), where the specific local context and culture shape the way people perceive, connect with, and attached to their surroundings. The levels of urban well-being are most commonly analysed through the domains of the urban environment relate to housing, community and neighbourhood satisfaction (McCrea et al., 2011). Public open spaces play an important role in shaping the everyday life of urban communities, being a vital element of the urban landscape that presents the spatial elicitation of the different aspects that shape a city's identity and the life within it. They are seen as a specific urban resource that can be characterised as a product of interaction between the economic, social, environmental, cultural, urban planning, and political domains of urban life (Páramo, 2017; Beck, 2009). Because of this, they can be viewed as a depiction of local life on a micro scale, helping to determine the dynamics of social, functional, environmental and economic aspects of a city (Salama et al., 2013). They are thus fundamental in assessing various aspects that shape the level of human satisfaction with place.

There are certainly numerous factors which play an important role in shaping and determining the QoUL of a place and its community. Contemporary conceptual frameworks of life quality encompass the material and immaterial, subjective and objective, individual and mutual elements that make up and shape an individual's life (Kabisch et al., 2018). Yet, there seems to be a lack of QoL indicators that are focussed on measuring the quality of open public spaces. Some qualities of urban open spaces that can be associated with the assessment, through the QoL perspective, include 
maintenance/condition, robustness, adaptability, design, legibility, sense of enclosure, availability of space for social interaction, availability of community resources, vitality and viability, functionality/functional quality, safety, comfort, ecological quality, attractiveness, relaxation, and amount and quality of green spaces (Figure 1). These more objective features are intertwined with the way users perceive their environment, which in turn shape their experience of the spatial qualities. Some of the more subjective possible indicators that enable correlating the attributes of life quality and urban open space quality are for example: individual feeling of safety, individual feeling of enjoyment, people's perception of where they live, perception of individual life conditions, feeling of attachment to people and place, individual sense of comfort, user experience, and individual sense of fulfilment (Beck, 2009). Therefore, this research strives to better understand the relationship between the users' perception of spatial qualities and the objective elements that shape a space, as a way towards acknowledging the need for integrating the level of urban space within the general framework of assessing the quality of urban life.

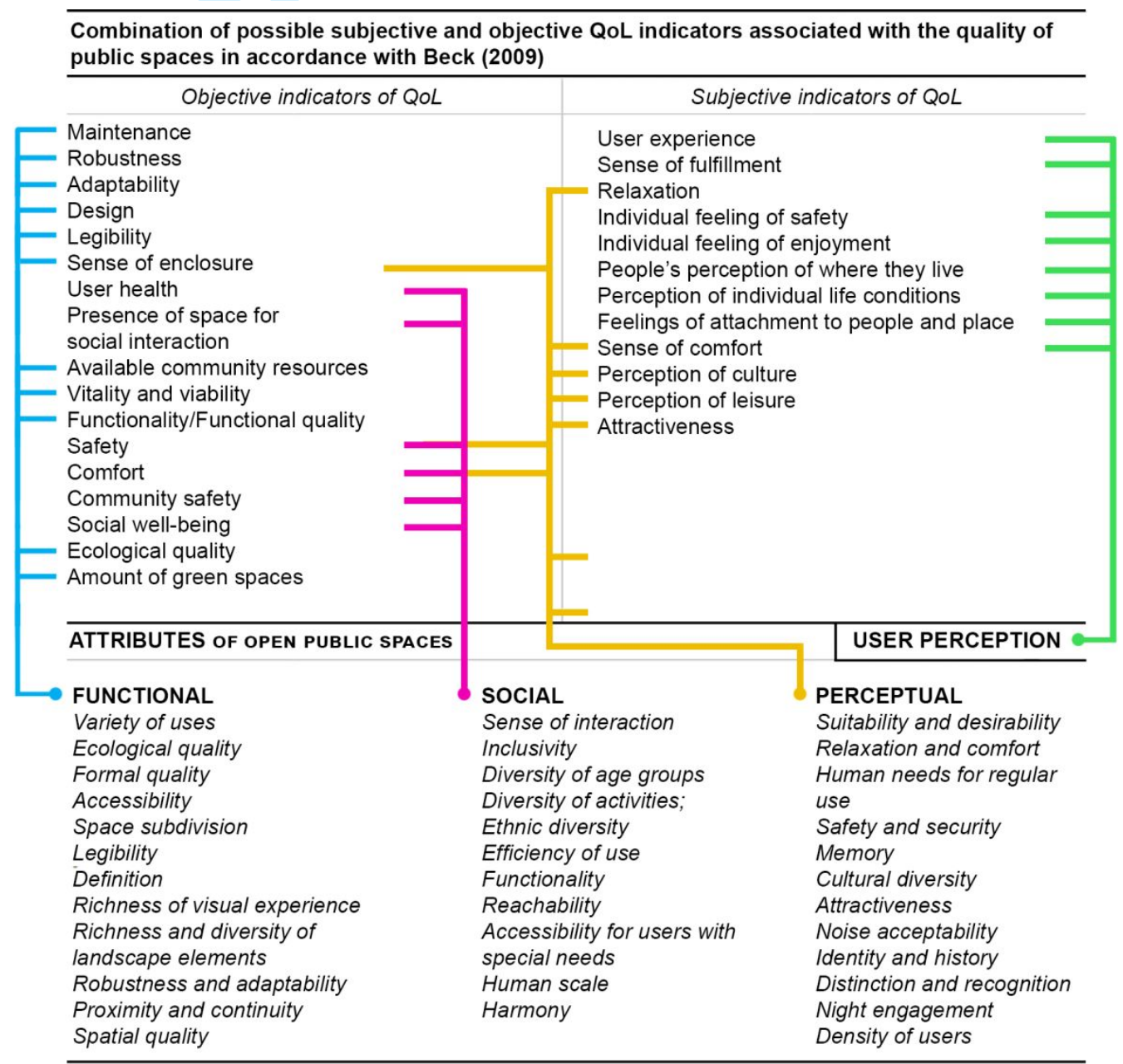

Figure 1 - Relation between a set of identified indicators of QoL associated with the quality of public spaces, suggesting the elements of the proposed methodological framework (Source: Authors).

\section{The context of Serbia and the examined open public spaces}

Serbia is located in the Western Balkan region of Europe, with an urban population that has been steadily growing since the rapid urban growth following the Second World War. Belgrade, the country's capital and largest city, and its metropolitan area are the permanent residence of approximately $25 \%$ of the entire country's population of approximately 9 million (Republički zavod 
za statistiku, 2019). Streets and public areas of Belgrade vary in size, shape, character and overall type, having developed under the influence of various ideological systems and cultures (Jovanović, Vuković, \& Mitrović, 2019). Within the local context, squares are mainly classified by their geometrical form and/or function (Djokić, 2009). The Urban Planning Institute of Belgrade conducted a study that encompassed all the different open public spaces within Belgrade's central zone of Stari Grad in 2009, aimed at understanding the ways in which they could be re-envisaged and better utilized (Urban Planning Institute of Belgrade, 2009). Since then, several major public architectural competitions concerned with many of Belgrade's most iconic public spaces were organized. This trend of developmental focus linked with the reconstruction of urban public spaces was reaffirmed with the adoption of the current Master Plan of Belgrade in 2016, recognising the need to better understand the city's possible future developmental strategies and paths through the creation of a comprehensive intertwined network of public open spaces (Urban Planning Institute of Belgrade, 2016).

The three squares identified for this study were selected based on their functional relevancy within the urban fabric, the range of activities, services and uses they encompass, and the range of different types of users they attract (Figure 2). These spaces were also selected in order to create a systematic comparison between the new and the old expressions of formal qualities of the city, with Slavija square representing the fully reconstructed space and manifestation of current urban ideals, Nikola Pašić square representing the former visions of pre-transitional urban quality, and Republic square being in the midst of complete spatial redevelopment. In this way, cumulative data related to the urban space level can gathered, enabling quantification of the overall perception of urban wellbeing, and in turn understand how open spaces may support the current conditions of urban life. Yet, the initial procedure was to outline each the overall profile and the spatial and functional attributes of each.

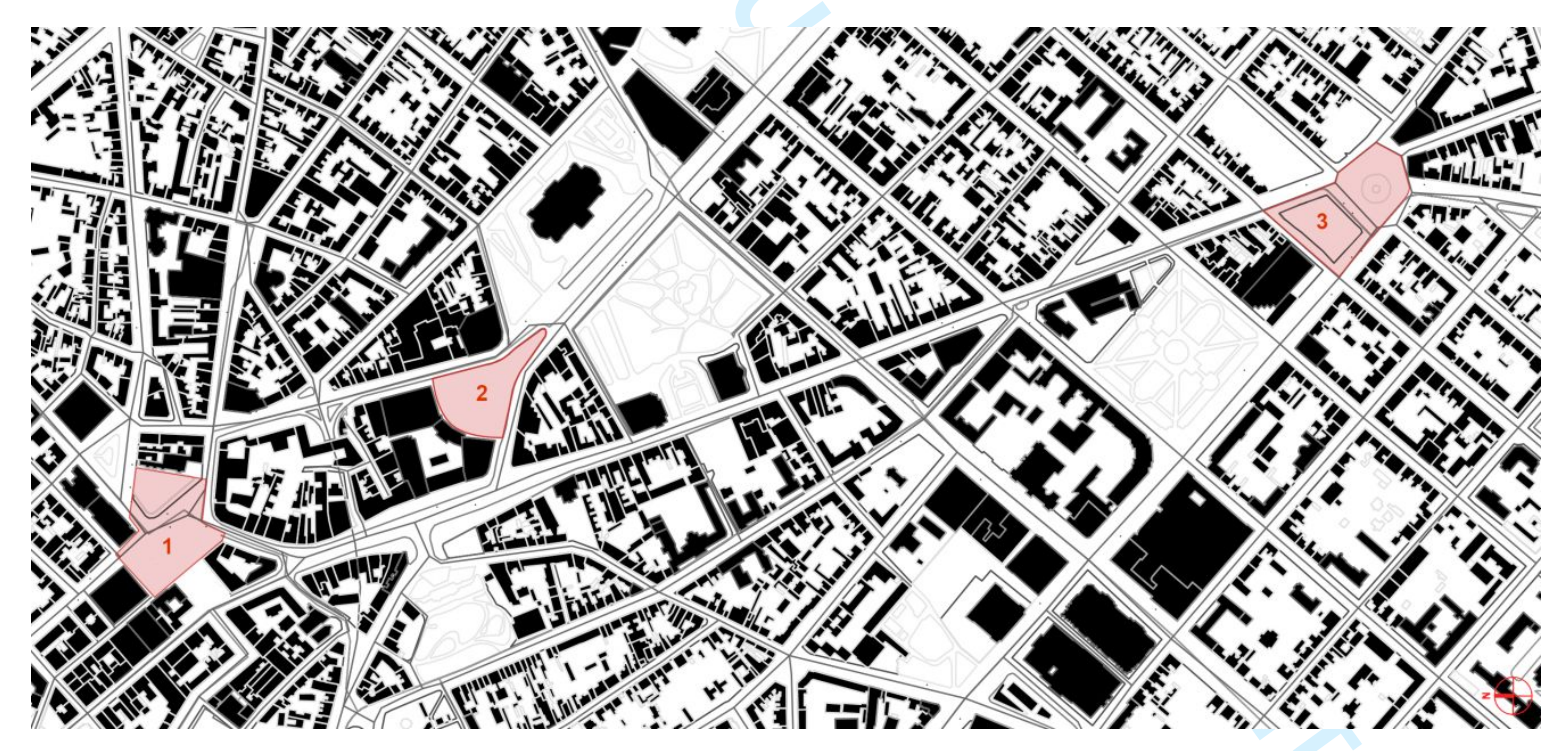

Figure 2 - Spatial disposition and relationship of Republic square (1), Nikola Pašić square (2), and Slavija square (3) (Source: Authors).

The reconstruction of Slavija square lasted between 2017 and 2018 and resulted in the space being partially reclaimed for pedestrians (Figure 3). The square is located on the intersection of Beogradska, Nemanjina, Kralja Milana, Mekenzijeva, Svetog Save, Bulevar Oslobodjenja and Deligradska streets, being bordered by Kralja Milutina street on its northwest side. The area where the square is located includes different amenities and activities, ranging from commercial spaces and various services to recreational spaces. The most distinct building that borders the square is the high-rise "Slavija" hotel, as well as historically significant buildings from the $19^{\text {th }}$ century, such as Vučo's house. The square encompasses the Slavija roundabout, with a central fountain, and the area 
of a tilted pedestrian plateau, with an enclosed commercial space beneath it, though not fully operational.

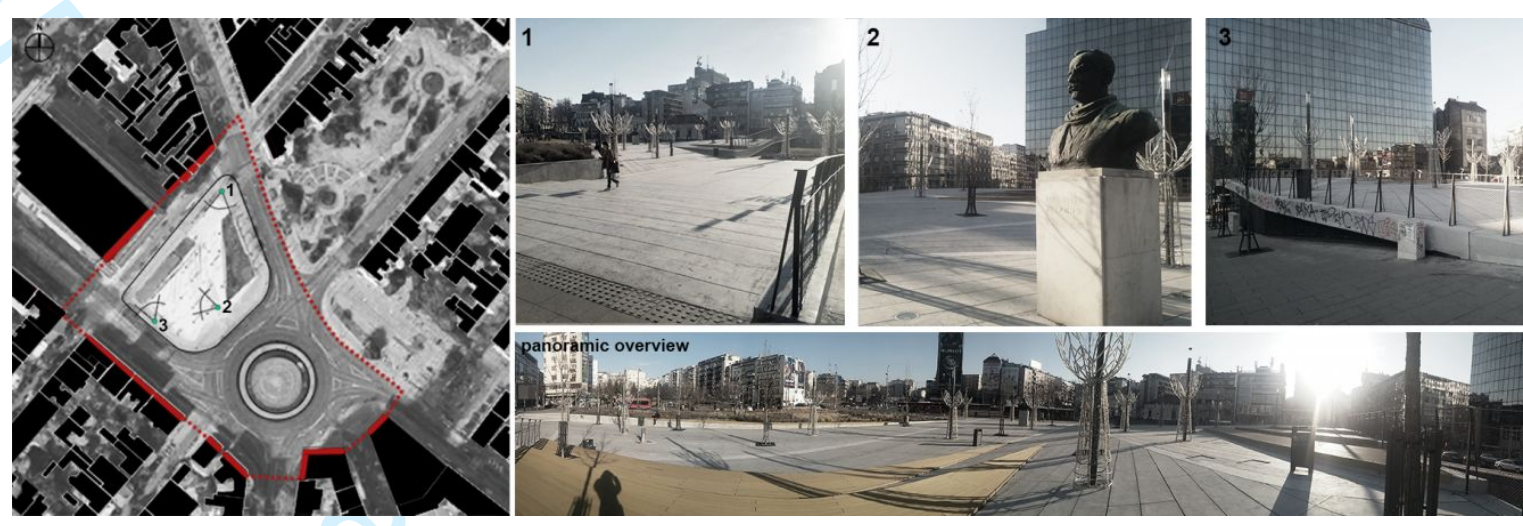

Figure 3 - Overview of Slavija square, its boundaries and surrounding area (Source: Authors).

Republic square is located at the very heart of Belgrade's historical centre. It can be viewed as the side extension of Knez Mihajlova pedestrian street, intersected by Vase Čarapića and Francuska streets and partially bordered by Kolarčeva street (Urban Planning Institute of Belgrade, 2009). It is the space where the National museum and National theatre of Serbia are located, being the two oldest and historically significant buildings (Figure 4). Republic square was first constructed in the $19^{\text {th }}$ century as one of the first planned squares in the city, along with the theatre building and the, now iconic, Knez Mihailo Monument. This open public space has since then been reshaped and rebuilt several times, with its most recent partial reconstruction completed in 2019. This project sparked controversy within the local community, partially due to its new open plan design and a general lack of diverse natural elements.
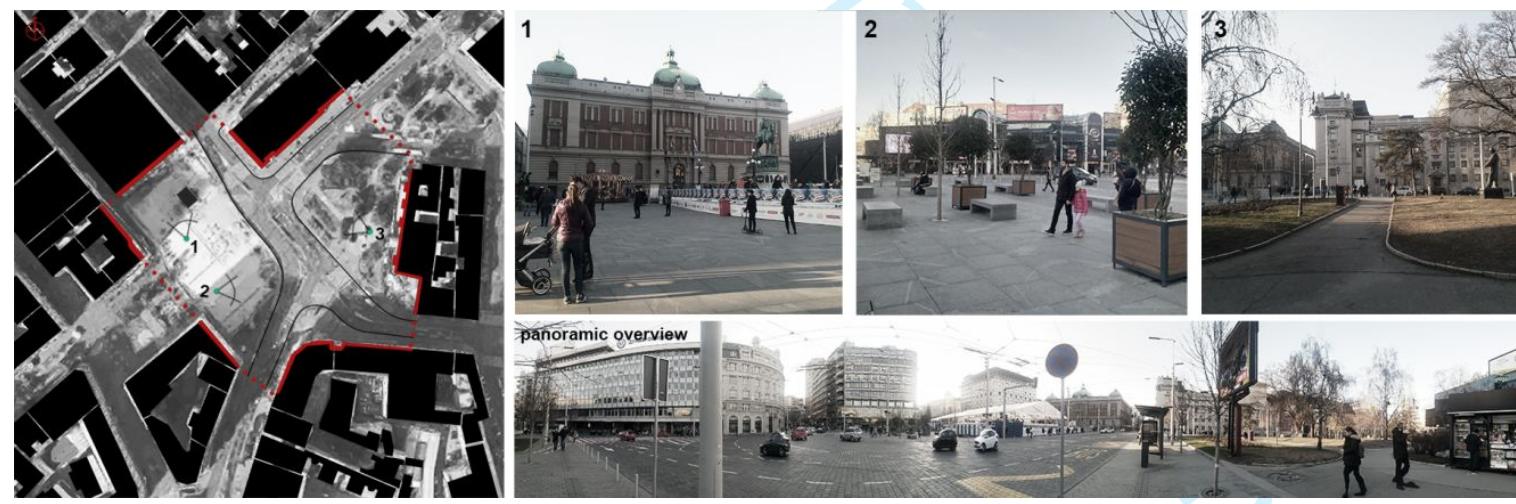

Figure 4 - Overview of Republic square, its boundaries and surrounding area (Source: Authors).

Nikola Pašić square is located in close proximity to Republic square, in front of the Dom Sindikata building that houses business, commercial and entertainment spaces (Figure 5). This open public space has a triangular form, with two out of its three perimeters being streets and the third is an oval building front. The space is connected to Terazije square via a pedestrian route going through the open lower levels of the Dom Sindikata building and through the inner courtyard of the encompassing urban block. Nikola Pašić square is also in close vicinity to the National history museum as well as the National Assembly building. Its most distinct feature is its elongated water fountain, built when the square was first established in the 1950s. Since then, the square has mostly kept its initial form and physical features, with the addition of the monument to Nikola Pašic erected in the 1990s, although a reconstruction of the plateau is planned in the near future. 

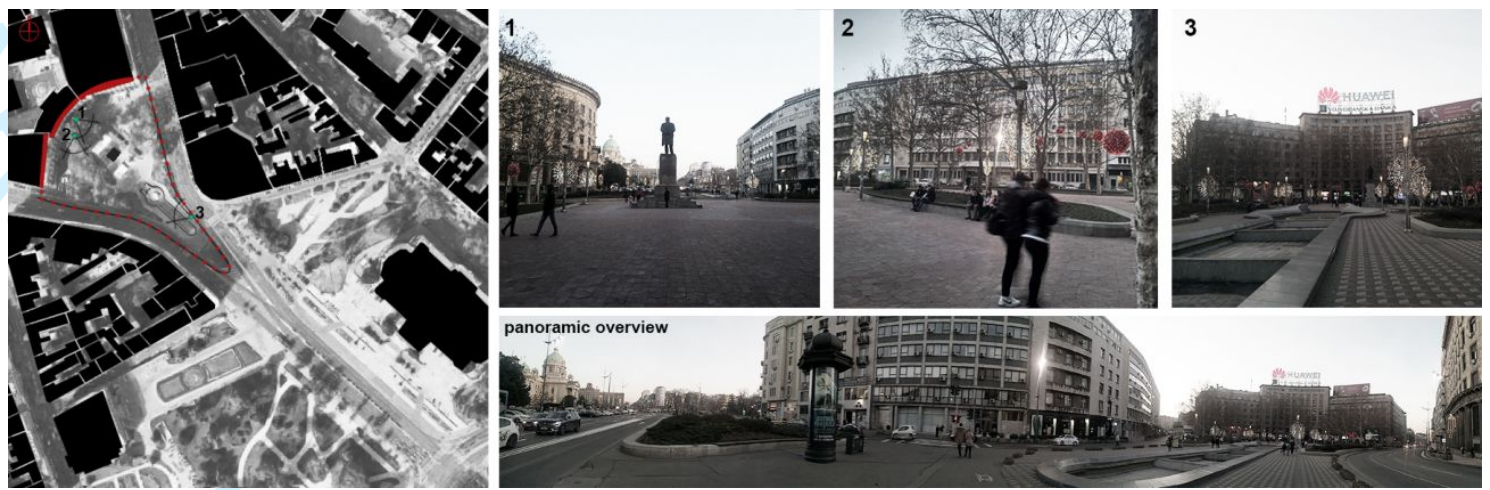

Figure 5 - Overview of Nikola Pašić square, its boundaries and surrounding area (Source: Authors).

\section{Methodology: A Multi-layered investigation mechanism}

The identified public open spaces were examined through a multi layered investigation process. The first step was to establish spatial profiles of the squares (Table 1) in order to better comprehend their underlying qualities and recognize their various spatial and generic attributes. Through this process insights into elements crucial for understanding how functional, social and perceptual elements of urban spaces are linked, were elucidated. This process was the basis for the next step of assessing a more general perception of urban spaces, and the way users interact with them. In surveying how the local community comprehends the environment they interrelate with the way in which contemporary urban life conditions are reflected in the public open spaces was assessed.

Table 1 - Summary of main spatial and functional attributes of the three spaces identified for analysis (Source: Authors).

\begin{tabular}{|c|c|c|c|c|}
\hline \multicolumn{2}{|r|}{ Space / Generic Spatial } & \multirow{2}{*}{$\begin{array}{c}\begin{array}{c}\text { Republic } \\
\text { square }\end{array} \\
1.47 \mathrm{ha}\end{array}$} & \multirow{2}{*}{$\begin{array}{c}\begin{array}{c}\text { Nikola Pašić } \\
\text { square }\end{array} \\
0.86 \text { ha }\end{array}$} & \multirow{2}{*}{$\begin{array}{c}\text { Slavija square } \\
1.90 \mathrm{ha}\end{array}$} \\
\hline \multirow{7}{*}{ 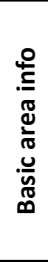 } & Total area & & & \\
\hline & Pedestrian area & $48 \%$ & $63 \%$ & $31 \%$ \\
\hline & Green area & $19 \%$ & $37 \%$ & $7 \%$ \\
\hline & Traffic area & $33 \%$ & $0 \%$ & $62 \%$ \\
\hline & Spatial sub-divisions & 3 & 4 & 3 \\
\hline & Water features & No & Yes & Yes \\
\hline & Geometrical shape & Irregular & Triangular & Radial \\
\hline \multirow{5}{*}{ 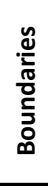 } & Perimeter & $515 \mathrm{~m}$ & $444 \mathrm{~m}$ & $588 \mathrm{~m}$ \\
\hline & Built front & $62 \%$ & $21 \%$ & $53 \%$ \\
\hline & Non-built front & $38 \%$ & $79 \%$ & $47 \%$ \\
\hline & Access points & 7 & 4 & 9 \\
\hline & Cohesion of architectural styles & High & High & Low \\
\hline \multirow{11}{*}{ 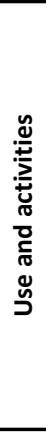 } & Residential & No & No & Yes \\
\hline & Leisure and recreation & Yes & Yes & Yes \\
\hline & Traffic & Yes & No & Yes \\
\hline & Business & Yes & Yes & Yes \\
\hline & Central activities & Yes & Yes & Yes \\
\hline & Culture and entertainment & Yes & Yes & No \\
\hline & Commercial services (shops) & Yes & No & Yes \\
\hline & Commercial services (catering) & Yes & Yes & Yes \\
\hline & Tourism & Yes & No & Yes \\
\hline & Seasonal manifestations & Yes & Yes & No \\
\hline & Main usage & $\begin{array}{c}\text { Central } \\
\text { activities }\end{array}$ & Culture & Traffic \\
\hline & Historical significance & Very High & Medium & High \\
\hline & Importance of urban node & High & High & Very High \\
\hline
\end{tabular}




\subsection{Walking Tour Assessment Procedure}

The walking tour assessment procedure follows a model established through earlier research in other contexts (Salama \& Azzali, 2015), where a framework was established to categorize urban spaces by their typology, architectural patterns, accessibility, activities and use, and user type through a number of functional, social and perceptual attributes (Salama et al., 2017a). This procedure is meant to establish a deeper understanding of the squares, to highlight their existing positive or negative qualities. Each of the three subsets of attributes encompass 12 factors that are meant to reflect the attributes of urban spaces. The 36 factors in total are each put against a scoring system and a four-point scale, where scores are assigned against each factor in terms of degree of appropriateness with the scores ultimately averaged out for each set of attributes.

It is recognized that some factors from one set of attributes may overlap with factors in another, so to ensure a process of verification and lessen the possibility of misinterpretation in assessing the factors or in the overall scoring system. By establishing the spatial profiles, we can primarily look into the objective attributes of open public spaces, while taking into account the domain of human perception. The three sets of attributes are as follows:

- Functional attributes: Variety of uses; ecological quality; formal quality; accessibility; space subdivision; legibility; definition; richness of visual experience; richness and diversity of landscape elements; robustness and adaptability; proximity and continuity; and spatial quality.

- Social attributes: Sense of interaction; inclusivity; diversity of age groups; diversity of activities; ethnic diversity; efficiency of use; functionality; reachability; accessibility; accessibility for users with special needs; human scale; and harmony.

- Perceptual attributes: Suitability and desirability; relaxation and comfort; human needs for regular use; safety and security; memory; cultural diversity; attractiveness; noise acceptability; identity and history; distinction and recognition; night engagement; and density of users.

\subsection{User perception assessment survey}

The next layer of assessment is used to get a better insight into the users' perception of the assessed spaces. This step of the analysis elucidates the subjective attributes of spaces. The user perception survey can be seen as photographic attitude survey where the understanding of the spatial experience if inferred based on photographs of the spaces. Building on the tools developed through previous research (Salama et al., 2017a\&b), sets of polar adjectives that aim to determine the users' understanding of what best describes the three examined squares were used. The participants in the survey responded to a number of paired adjectives relevant to each of the three squares. There are: inviting/uninviting; iconic/ordinary; distinctive/indistinctive; vibrant/boring; urban/peripheral; familiar/unfamiliar; pleasing/unpleasing; and restful/stressful. The participants were also asked which of the three squares they most and least visit and like, as well as to identify which one represents Belgrade the best in their opinion.

\section{Discussion of key findings}

\subsection{Functional attributes}

The walking tour assessment of Republic square reveals somewhat contradicting results and a disjointed composition of its main plateau in front of the Nation Theatre building and its more secondary park area (seen as an integral part of the square by the Urban Planning Institute of 
Belgrade). While it encompasses a wide range of activities appropriate for a central town square, its disparity of street furnishing clashes with its spatial and contextual setting. Its most appealing functional quality is its proximity to important attractions, good local connections, and its general spatial accessibility (Table 2). These qualities however contradict with its spatial definition and formal readability, with the space merging with its bordering streets and shying away from its wider spatial confines, showing mostly unsuitable boundaries between the pathways meant for pedestrian use and those for vehicles. While the formal openness of the square panders to the adaptability of the area to accommodate different temporary spatial activities, its general lack of additional landscape elements and poor choice of used materials make the location's ecological and formal quality as well as it's visual experience rather unpleasing, all drastically contributing to lowering its overall spatial quality and, furthermore, the sense of individual comfort. The square's general significance within the urban milieu of Belgrade is widely due to its long cultural-historical impact, which serves towards enhancing its usability and crowdedness throughout the day. Republic square is however located near major connection routs and is quite easily reachable by different forms of transport and is also relatively easily accessible to users of different abilities.

With Slavija square being just recently spatially reclaimed as a pedestrian open public space, its significance within the local urban network has significantly improved. Located right next to the busiest transit junctions in the city of Belgrade, its immediate environment is characterised by the presence of perpetual traffic. The space of the square can clearly be divided into the pedestrian area, shaped by a slightly lifted and tilted plateau, and the area meant for vehicles, being distinct for its merry-go-round with a fountain in its centre. The dominant presence of motor vehicles makes accessibility to the space via different routes limited, while the positions of the surrounding streets clearly define the boundaries of the pedestrian square. Being an important node in the public transport system, important attractions, cultural and public buildings, and the different activities in the close proximity of Slavija square are quite easily reachable, making the location very well connected. The space of the plateau is however lacking in terms of the variety of use, being meant mainly for relaxation with no distinct additional features within or bordering it, thus heavily impacting the square's overall spatial quality. The tilt of the pedestrian area with its landscape elements and presence of trees and green areas contributes greatly to the visual experience of the space. However, these features also restrict the level of adaptability of the space, with the choice of the paving materials and the way the natural elements are bounded tightly within them heavily impacting its ecological quality, alongside with the bordering busy streets that have a significant impact on air, noise and ground pollution.

Table 2 - Scores of various factors underlying functional attributes of the three squares (Source: Authors).

\begin{tabular}{|c|c|c|c|c|c|c|c|c|c|c|c|c|c|}
\hline $\begin{array}{l}\text { Functional } \\
\text { Attributes }\end{array}$ & 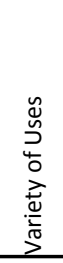 & 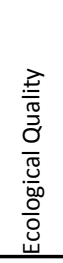 & 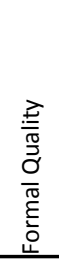 & 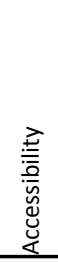 & 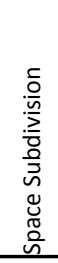 & 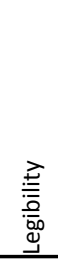 & 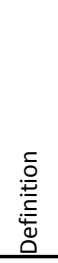 & 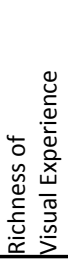 & 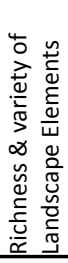 & 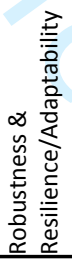 & 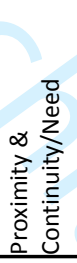 & 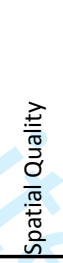 & 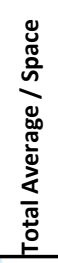 \\
\hline $\begin{array}{l}\text { Republic } \\
\text { square }\end{array}$ & 3.00 & 0.75 & 2.25 & 3.50 & 1.25 & 3.25 & 2.50 & 2.25 & 0.75 & 2.50 & 3.50 & 1.75 & 2.27 \\
\hline $\begin{array}{l}\text { Slavija } \\
\text { square }\end{array}$ & 1.25 & 1.50 & 1.75 & 1.75 & 2.00 & 2.50 & 2.75 & 1.75 & 2.50 & 1.25 & 3.00 & 2.25 & 2.02 \\
\hline Nikola & & & & & & & & & & & & & \\
\hline $\begin{array}{c}\text { Pašić } \\
\text { square }\end{array}$ & 2.75 & 3.75 & 3.50 & 3.50 & 3.25 & 3.25 & 3.50 & 3.25 & 3.25 & 3.00 & 3.25 & 3.25 & 3.29 \\
\hline Descripti & & \multicolumn{3}{|c|}{$\leq 1.00$ (Highly Inappropriate) } & \multicolumn{3}{|c|}{$>1.00-2.00$ (Inappropriate) } & \multicolumn{3}{|c|}{$>2.00-3.00$ (Appropriate) } & \multicolumn{3}{|c|}{$>3.00$ Highly Appropriate } \\
\hline
\end{tabular}


Nikola Pašić square stood out in the walking tour assessment as the one with the highest overall assessment scores (Table 2). Being located in close proximity to the heart of the city centre, it is close to many of the city's important attractions and a great variety of different uses. The square is legible and has a clear spatial definition, bordered by two of the busiest streets in Belgrade and a concave building front pierced by a pedestrian passage, contributing to effective accessibility. The location is subdivided, offering clear routes for pedestrian transit alongside spaces for seating and relaxation. The space has an acceptable variety of landscape elements, with the dominant one alongside the greenery, being its centrally positioned fountain. The square's open areas make it suitable to host different seasonal activities, making it functionally adaptable. The presence of trees and water features elevates the ecological quality and the robustness of the space, while also focusing the visual experience towards the square and its bordering buildings and away from the streets traffic. The surrounding facilities of the square house commercial, business, cultural and leisure facilities offering the users a good variety of use. Overall, Nikola Pašić square has a unique formal and spatial quality that is highly appropriate for the location of this public open space.

\subsection{Social attributes}

With its proximity to public transportation routes and many different attractions and central activities nearby, Republic square serves as an important and mostly highly functional pedestrian transit area, while its aforementioned local cultural status contributes towards shaping it as a place of interaction and leisure stay. In accommodating some of Belgrade's iconic landmarks and a variety of surrounding activities, Republic square sparks a sense of general spatial inclusivity, with its users varying in age, gender and ethnicity (Table 3 ). Its overall social qualities and significance are only lowered by its lack of spatial features and urban furniture elements, which don't correspond with the human scale and the users' most basic needs. This discrepancy creates a general sense of spatial disharmony, undeniably contributing to a sense of detachment between individuals and their physical environment. The openness of its main plateau allows the space to host many different gatherings and non-permanent activities, attracting a diverse type of users through different times of the year. The downside of this is presented when the additional temporary use spatially devours the majority of the square, making interaction within it limited to its border areas.

When considering the social attributes of Slavija square, it is important to highlight that the area is used mainly as a transit point by the great majority of the users. This fact contributes to the general social dynamic within the space, where the sense of interaction isn't actually felt. Yet, the space does fulfil this transitory function, although the presence of the elevated plateau obstructs and unfavourably shapes pedestrian pathways, lowering its efficiency of use as well as its accessibility to special users. The scarcity of street furniture contributes to the social dynamics within the space, with the upper areas of the plateau lacking additional features besides seating. Slavija square is seen as an inclusive space, where different groups of users intertwine during their daily commutes, although with a clear dominant presence of users between the ages of $16-25$ and 26 - 49 through the day. The space isn't seen as up to the human scale, due to its formal attributes inability to contribute to fulfilling the primary or additional needs of its users (Table 3). The space is dominantly shaped as a place for interaction and relaxation, while lacking the proper features that would allow users to adequately interact and engage. All this plays a part in underlining the disharmony between the vehicular and pedestrian designated spaces, instead of trying to mitigate it.

Not so busy during the day as the other two squares, Nikola Pašic square's position within the urban matrix and the available cultural activities within it still attract a wide array of users of different age groups, ethnic backgrounds and various levels of mobility. It serves as both an important pedestrian transit point as well as a small urban oasis within the busy city centre. With significant public transportation nodes in its close proximity the location is easily reachable from different areas of the city, while surrounding connections contribute to its accessibility and efficiency of use. There is a 
clear sense of social interaction within the space, especially during late day and evening hours (Table 3). Generally, the spatial features of the square are in harmony with the needs of its users, being quite clearly made up to the human scale.

Table 3 - Scores of various factors underlying social attributes of the three squares (Source: Authors).

\begin{tabular}{|c|c|c|c|c|c|c|c|c|c|c|c|c|c|}
\hline $\begin{array}{c}\text { Social } \\
\text { Attributes }\end{array}$ & 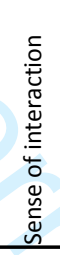 & $\begin{array}{l}\vec{z} \\
\frac{\vec{y}}{\underline{\underline{z}}} \\
\underline{\underline{\underline{c}}} \\
\end{array}$ & 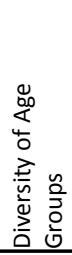 & 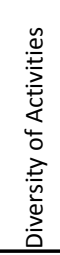 & 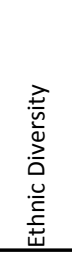 & 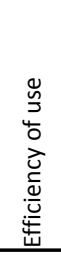 & 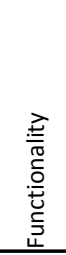 & 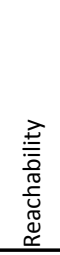 & 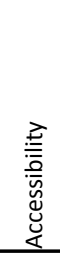 & 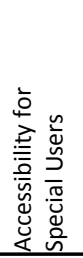 & 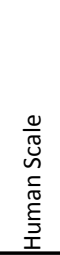 & 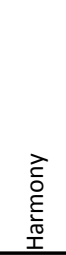 & 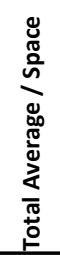 \\
\hline $\begin{array}{l}\text { Republic } \\
\text { square }\end{array}$ & 3.50 & 4.00 & 4.00 & 3.00 & 3.25 & 2.50 & 2.25 & 4.00 & 3.75 & 4.00 & 2.75 & 2.00 & 3.25 \\
\hline $\begin{array}{l}\text { Slavija } \\
\text { square }\end{array}$ & 0.75 & 3.00 & 2.75 & 1.25 & 2.00 & 1.50 & 1.50 & 3.00 & 2.75 & 1.25 & 1.50 & 1.75 & 1.92 \\
\hline $\begin{array}{l}\text { Nikola } \\
\text { Pašić } \\
\text { square }\end{array}$ & 3.00 & 4.00 & 3.50 & 2.75 & 2.00 & 4.00 & 3.50 & 3.75 & 3.75 & 4.00 & 4.00 & 3.50 & 3.46 \\
\hline Descriptio & & \multicolumn{3}{|c|}{$\leq 1.00$ (Highly Inappropriate) } & \multicolumn{3}{|c|}{$>1.00-2.00$ (Inappropriate) } & \multicolumn{3}{|c|}{$>2.00-3.00$ (Appropriate) } & \multicolumn{3}{|c|}{$>3.00$ Highly Appropriate } \\
\hline
\end{tabular}

\subsection{Perceptual attributes}

The sense of socio-spatial incoherence is quite easily observable in regard to Republic square, best seen through the examination of the square's perceptual attributes. The square does not truly meet some of the basic individual needs that would heighten the level of attractiveness of the space. While the sense of safety and personal security are at a high level, due to the concentration of various groups of users throughout the day combined with the openness and observability of the space and its satisfactory level of illumination and engagement during nighttime, this open public space lacks to incite the feeling of relaxation, and most importantly comfort, within it (Table 4). The level of desirability of the location is primarily heightened not through its formal or spatial attributes, but through its historical significance that has shaped its distinct identity. Being a space of cultural significance, Republic square is ingrained within the memory of the local populace as one of the most important open spaces within the city. Yet, its readability as a space of significance isn't clearly observable through the users' everyday interaction with the space.

This type of dichotomy is also observable in Slavija square. While the space is distinct and recognisable due to its importance within the transit network of the city, contributing to a very high density of users through the day and night times, the sense of relaxation and comfort are utterly lost, while the needs of individual commuters aren't properly met (Table 4). The surrounding area of the square is defined through buildings and spaces that hail from different eras of Belgrade's development. Still, the qualities related to memory and identity associations, or cultural significance and historical relevance aren't truly observable. This further contributes to the desirability, acceptability and attractiveness of the location, making it overarchingly characterless, with the central water feature and its surrounding heavy traffic the main spatial feature to visually stand out against its overall urban scene.

Nikola Pašić square has a clear separation between pedestrian and vehicle pathways that along with the presence of natural elements contribute towards shaping its perceptual qualities, making it a pleasant and comfortable space to interact with and within. Its high density of use doesn't invoke a sense of crowdedness or lack of safety, making it to be perceived as desirable and attractive for a longer stay (Table 4). Its position, surrounding and encompassing attractions also serve in shaping its unique identity, making it a memorable, unique and distinct location within Belgrade. Overall, Nikola 
Pašic square fulfils both the primary and additional needs of its users, while also accentuating the cultural and historical significance of its surroundings.

Table 4 - Scores of various factors underlying perceptual attributes of the three squares (Source: Authors).

\begin{tabular}{|c|c|c|c|c|c|c|c|c|c|c|c|c|c|}
\hline $\begin{array}{l}\text { Perceptual } \\
\text { Attributes }\end{array}$ & 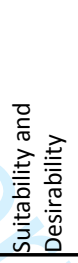 & 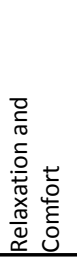 & 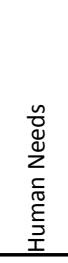 & 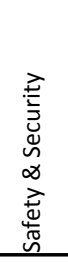 & 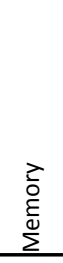 & 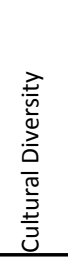 & 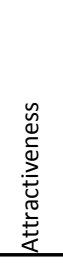 & 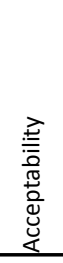 & 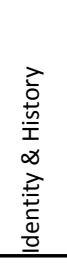 & 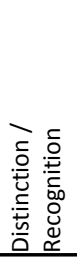 & 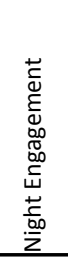 & 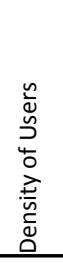 & 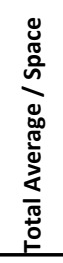 \\
\hline $\begin{array}{l}\text { Republic } \\
\text { square }\end{array}$ & 2.25 & 1.50 & 1.50 & 3.75 & 2.25 & 2.25 & 2.00 & 1.75 & 3.75 & 3.50 & 3.75 & 3.75 & 2.67 \\
\hline $\begin{array}{l}\text { Slavija } \\
\text { square }\end{array}$ & 1.25 & 0.75 & 1.00 & 3.00 & 1.25 & 1.50 & 1.75 & 1.50 & 1.25 & 3.25 & 3.00 & 4.00 & 1.96 \\
\hline Nikola & & & & & & & & & & & & & \\
\hline $\begin{array}{c}\text { Pašić } \\
\text { square }\end{array}$ & 3.00 & 3.75 & 3.50 & 3.50 & 3.25 & 2.25 & 2.75 & 4.00 & 3.50 & 3.25 & 3.50 & 3.00 & 3.27 \\
\hline Descripti & & \multicolumn{3}{|c|}{$\leq 1.00$ (Highly Inappropriate) } & \multicolumn{3}{|c|}{$>1.00-2.00$ (Inappropriate) } & \multicolumn{3}{|c|}{$>2.00-3.00$ (Appropriate) } & \multicolumn{3}{|c|}{$>3.00$ Highly Appropriate } \\
\hline
\end{tabular}

\subsection{Users perception of public open spaces}

A total of 37 individuals participated in the survey and the responses received contribute to a better understanding of how users perceive and comprehend their urban surroundings. The user perception assessment survey was conducted in January of 2020 and almost all of the participants were living in Belgrade at the time the survey was conducted.

Table 3 - The overall profile of respondents to the survey (Source: Authors).

\begin{tabular}{|c|c|c|}
\hline Group of responders & Categories & Percentage \\
\hline \multirow{3}{*}{ Age group } & $16-25$ & $2,7 \%$ \\
\cline { 2 - 3 } & $26-49$ & $78,4 \%$ \\
\cline { 2 - 3 } & $50+$ & $18,9 \%$ \\
\hline \multirow{2}{*}{ Gender } & Female & $73 \%$ \\
\cline { 2 - 3 } & Male & $27 \%$ \\
\hline $\begin{array}{c}\text { Resident of Belgrade } \\
\text { versus other cities }\end{array}$ & Belgrade & $97,3 \%$ \\
\cline { 2 - 3 } & Other & $2,7 \%$ \\
\hline
\end{tabular}

All of the three squares were scored almost equally in regard to their familiarity, while the majority of the respondents identified Nikola Pašić square as the least central out of the three. In terms of their vibrancy, Republic square, located within the very heart of Belgrade and hosting two of the city's most distinct cultural buildings and in close proximity to many major attractions, scored the lowest by far and was seen as predominantly boring, as well as simple, not very distinct and the least iconic. The least boring and indistinguishable open space according to the survey is Nikola Pašić square, also being the one undoubtedly considered the most pleasing, restful and vibrant.

Slavija square received the lowest scores in regard to its perceived complexity and restfulness, while also being marked as unpleasing by almost half of the respondents. This can be attributed to the fact that it is being the busiest transit point out of the three squares, where the stressfulness of rushhour traffic seems to be the most striking feature. On the other hand, it was marked as the most distinct, complex, as well as quite unusual in comparison to the other two. Despite these perceived characteristics, the majority of the participants didn't consider it as inspiring, ultimately rating it as the most uninviting (Figure 6). 
The results of the photographic attitude survey demonstrate an overwhelming sense of uncertainty with respect to understanding the squares as balanced spaces that convey desired feelings. This is best observed when analysing the responses on which spaces users liked or disliked the most and think that they represent the city the best. The respondents overwhelmingly identified Republic square (Figure 7), despite dominantly giving it attributes that do not adequately fit with a space of such perceived significance. The users' experience of Slavija square does however adequately correspond with the attributes most frequently attributed to it. This occurrence points us towards the conclusion that collective memory plays an important role in shaping the users' overall perception of a space, more than the individual comprehension of the selected attributes and thus can give results that don't fully correspond with the sense of an individual's comfort or overall satisfaction with and within a space.

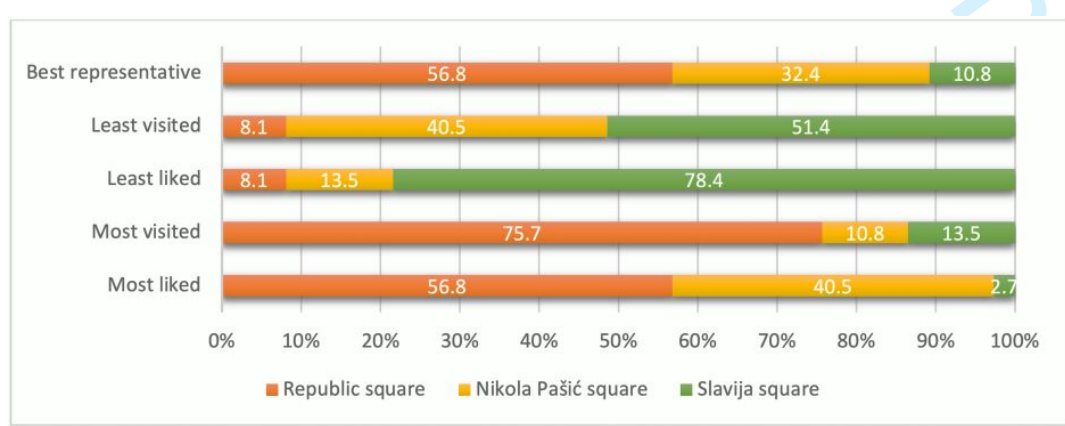

Figure 7 - Users' description of the spaces as they relate to the city and to their experience (Source: Authors). 


\section{Conclusion}

While the sample size is not necessarily applicable to generalise a case, the data gathered through this conveys a general sense of imbalance in elements that are attributed to an overall acceptable level of urban space quality in Belgrade. The challenges mainly arise from the contemporary gap between design and user needs, where the focus of urban development seems to depart from the acknowledgement of certain community requirements. The examined urban spaces attest to a specific user-space relationship, where both feelings of the surveyed users and the general attributes of their environment are mostly in conflict. This is most clearly recognisable in the examination of Republic square, the space most overwhelmingly liked by the majority of individuals, whose functional attributes do not have an acceptable level of diversity and quality in relation to its position and importance within the urban matrix. This notion is further confirmed by the way the respondents rated the space in the photographic attitude survey, where it wasn't truly seen as inviting in nature. In turn, if the state of the open urban environment as the physical manifestation and extension of QoL is an imperative, then the intended modernization and modern means of upgrading the urban environment have contributed to a lower standard of quality of urban life. I this respect, it is important to highlight that there was a contradiction between the contemporary means of development and the former ideals of city growth in Belgrade's past. This has certainly contributed to a disjointed urban fabric where the old and the new can sometimes stand in opposition to one another unable to find a well-functioning middle ground.

Understanding the connections between quality of life and quality of public spaces is vital in working towards regenerating and improving the public realm and concomitantly the lives of the local community. This study establishes the possibility of practically improving the urban space level by minor pin-pointed, small scale interventions that work towards bettering the spatial attributes of the urban environment that were deemed to be unacceptable or at a lower level in general comparison. In examining the subjective features that make up an urban public space and methodically showcasing the perceived attributes of a certain place, the spatial elements that contribute to the users' overall sense of comfort within an environment can be discerned and understood. In this sense, conclusions can be made about which physical elements are deemed as essential, needed or are lacking, pointing towards a better understanding of the urban scale while considering userscentred urban interventions and developments. While this study elaborates key aspects of the human dimension of urban environments, it presents itself as a preliminary step towards a wider scope study which engages with more spaces, with further dimensions of quality of urban life as it relates to urban spaces, and with a larger population sample. This would yield findings that enable future effective decision making on urban living and quality in Belgrade. 


\section{References}

Beck, H., (2009), "Linking the quality of public spaces to quality of life", Journal of Place Management and Development, vol. 2 no. 3, pp. 240-248. https://doi.org/10.1108/17538330911013933

Djokić, V., (2009), Urban Typology: City Square in Serbia. Univerzitet u Beogradu, Arhitektonski Fakultet, Belgrade.

Eurostat, (2015), Quality of Life - Facts and Views, Publications Office of the European Union, Luxemburg.

Felce, D. and Perry, J., (1995), "Quality of Life: Its Definition and Measurement", Research in Developmental Disabilities, vol. 16 no. 1, pp. 51-74. https://doi.org/10.1016/0891-4222(94)00028-8

Jovanović, P., Vuković, T. and Mitrović, B., (2019), "Searching for the Code of New Belgrade's Open Space: Case study of Block 37", in Places and Technologies 2019 The 6th International Academic Conference on Places and Technologies Proceedings, University of Pécs Faculty of Engineering and Information Technology, Pécs, pp. 279-286.

Kabisch, S.; Koch, F.; Gawel, E.; Haase, A.; Knapp, S.; Krellenberg, K.; and Zehnsdorf, A., (2018), "Introduction: Urban Transformations - Sustainable Urban Development Through Resource Efficiency, Quality of Life and Resilience", in Kabisch, S. et al (Ed.), Urban Transformations - Sustainable Urban Development Through Resource Efficiency, Quality of Life and Resilience, Springer International Publishing, Cham, Switzerland, pp. xvii-xxviii.

MacLean, L. and Salama, A. M., (2019), "Towards a Context Specific and Multidimensional Quality of Urban Life Model", Open House International, vol. 44 no. 1, pp. 25-33. https://doi.org/10.1108/OHI-01-2019-B0004

Marans, R. and Stimson, R., (2011), "An Overview of Quality of Urban Life", in Marans, R. and Stimson, R. (Ed.) Investigating Quality of Urban Life: Theory, Methods, and Empirical Research. Springer Science+Business Media B.V., pp. 1-29.

Marans, R., (2015), "Quality of urban life \& environmental sustainability studies: Future linkage opportunities", Habitat International, vol. 45, pp. 47-52. https://doi.org/10.1016/j.habitatint.2014.06.019

McCrea, R., Marans, R., Stimson, R. and Western, J., (2011), "Subjective Measurement of Quality of Life Using Primary Data Collectionand the Analysis of Survey Data", in Marans, R. and Stimson, R. (Ed.), Investigating the Quality of Urban Life: Theory, Methods, and Empirical Research, Springer Science+Business Media B.V., pp. 5575.

Pacione, M., (2003), "Urban environmental quality and human wellbeing-a social geographical perspective", Landscape and Urban Planning, Vol. 65, pp. 19-30.

Páramo, P., (2017), "The City as an Environment for Urban Experiences and the Learning of Cultural Practices", in Fleury-Bahi, G., Pol, E. and Navarro, O. (Ed.), Handbook of Environmental Psychology and Quality of Life Research, Springer International Publishing, pp. 275-290. https://doi.org/10.1016/S0169-2046(02)00234-7

Republički zavod za statistiku, (2019), "National census data”, available at: https://www.stat.gov.rs/srlatn/oblasti/popis/popis-2011/ (accessed 15 November 2019).

Rink, D., Kabisch, S., Koch, F. and Krellenberg, K., (2018), "Exploring the Extent, Selected Topics and Governance Modes of Urban Sustainability Transformations", in Kabisch, S et al. (Ed.), Urban Transformations Sustainable Urban Development Through Resource Efficiency, Quality of Life and Resilience, Springer International Publishing, pp. 3-20.

Romice, O., Thwaites, K., Porta, S. and Greaves, M., (2017), "Urban Design and Quality of Life”, in Fleury-Bahi, G., Pol, E. and Navarro, O. (Ed.), Handbook of Environmental Psychology and Quality of Life Research, Springer International Publishing, pp. 241-274.

Salama, A. and Azzali, S., (2015), "Examining attributes of urban open spaces in Doha", in Proceedings of the ICE - Urban Design and Planning, vol. 168 no. 2, pp. 75-87. https://doi.org/10.1680/udap.14.00011 
Salama, A., Remali, A. and MacLean, L., (2017a), “Characterisation and Systematic Assessment of Urban Open Spaces in Glasgow City Centre", SPATIUM, vol. 37, pp. 22-33. https://doi.org/10.2298/SPAT1737022S

Salama, A., Remali, A. and MacLean, L., (2017b), “Deciphering Urban Life: A Multi-Layered Investigation of St. Enoch Square, Glasgow City Centre", Archnet-IJAR: International Journal of Architectural Research, vol. 11 no. 2, pp. 137-156.

Salama, A.M., Khalfani, F. \& Al-Maimani, A., (2013), "Experiential assessment of urban open spaces in Doha", Open House International, vol. 38, no. 4, pp. 47-57. https://doi.org/10.1108/OHI-04-2013-B0006

Stimson, R. and Marans, R., (2011), “Objective Measurement of Quality of Life Using”, in Marans, R. and Stimson, R. (Ed.), Investigating Quality of Urban Life: Theory, Methods, and Empirical Research, Springer Science+Business Media B.V., pp. 33-53.

Theofilou, P., (2013), "Quality of Life: Definition and Measurement", Europe's Journal of Psychology, vol. 9, pp. 150-162. https://doi.org/10.5964/ejop.v9i1.337

Urban Planning Institute of Belgrade, (2009), "Study of Belgrade Public Spaces Phase I - Analysis of Public Spaces in the Old Town of Belgrade", available at:

https://urbel.com/uploads/Studije/javni_prostori_studija.pdf (accessed 14 January 2020)

Urban Planning Institute of Belgrade, (2016), "Belgrade Master Plan 2016", available at:

https://www.beoland.com/en/plans/master-plan-belgrade/ (accessed 13 October 2019)

van Kamp, I., Leidelmeijer, K., Marsmana, G. and de Hollander, A., (2003), “Urban environmental quality and human well-being Towards a conceptual framework and demarcation of concepts; a literature study", Landscape and Urban Planning, vol. 65, pp. 5-18. https://doi.org/10.1016/S0169-2046(02)00232-3

Wiedmann, F., Mirincheva, V. \& Salama, A.M., (2013), "Urban reconfiguration and revitalisation: Public mega projects in Doha's historic centre", Open House International, vol. 38, no. 4, pp. 27-36.

https://doi.org/10.1108/OHI-04-2013-B0004 
Figure 1 - Relation between a set of identified indicators of QoL associated with the quality of public spaces,

Combination of possible subjective and objective QoL indicators associated with the quality of public spaces in accordance with Beck (2009)

Objective indicators of QoL Subjective indicators of QoL

- Maintenance

Robustness

- Adaptability

Design

Sense of enclosure

User health

Presence of space for

social interaction

- Available community resources

Vitality and viability

unctionality/Functional quality

Safety

Comfort

Community safety

Social well-being

Ecological quality

Amount of green spaces

ATTRIBUTES OF OPEN PUBLIC SPACES

Variety of uses

Ecological quality

Formal quality

Accessibility

Legibility

Definition

Richness of visual experience

Richness and diversity of

landscape elements

Robustness and adaptability

Proximity and continuity

Spatial quality

\section{User experience}

Sense of fulfillment

- Relaxation

Individual feeling of safety

Individual feeling of enjoyment

People's perception of where they live

Perception of individual life conditions

Feelings of attachment to people and place

- Sense of comfort

- Perception of culture

Perception of leisure

- Attractiveness

SOCIAL

Sense of interaction

Inclusivity

Diversity of age groups

Diversity of activities

Efficiency of use

Functionality

Reachability

Accessibility for users with

special needs

Human scale

Harmony

\section{USER PERCEPTION}

PERCEPTUAL

Suitability and desirability

Relaxation and comfort

Human needs for regular

use

Safety and security

Memory

Cultural diversity

Attractiveness

Noise acceptability

Identity and history

Distinction and recognition

Night engagement

Density of users

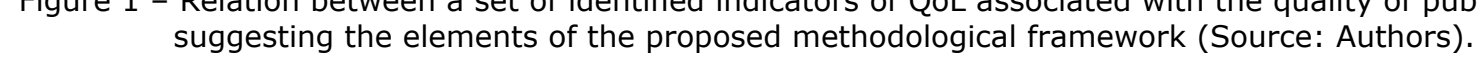

$155 \times 149 \mathrm{~mm}(300 \times 300 \mathrm{DPI})$ 


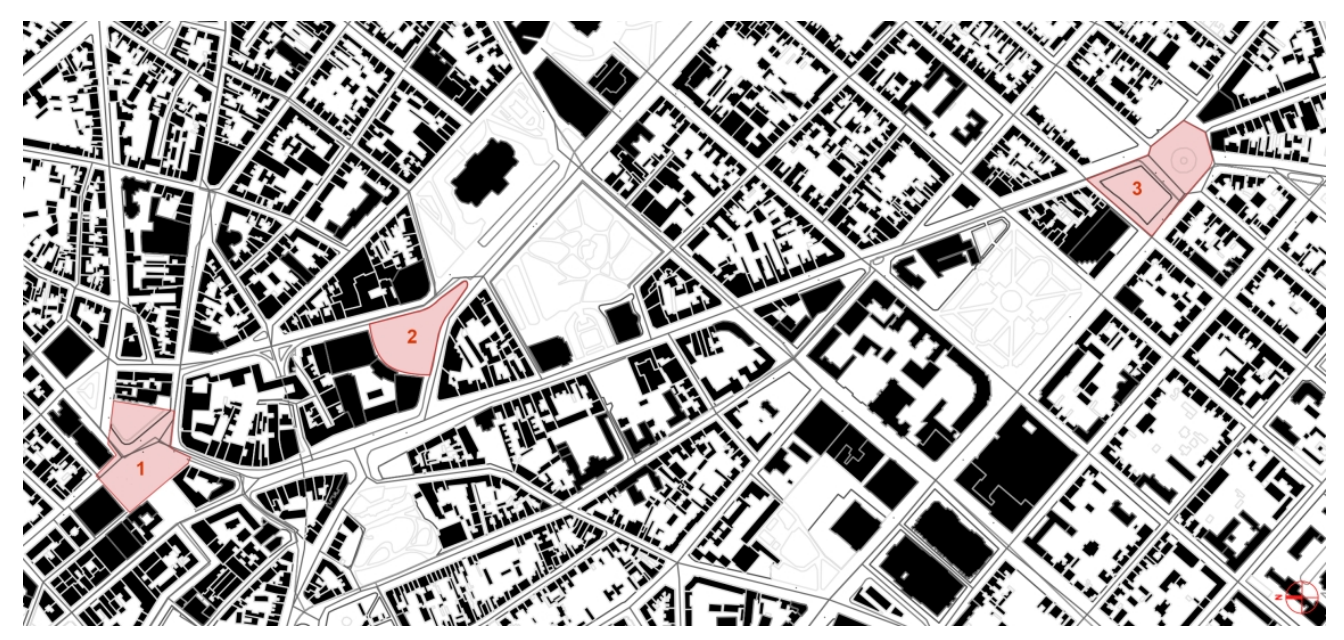

Figure 2 - Spatial disposition and relationship of Republic square (1), Nikola Pašić square (2), and Slavija square (3) (Source: Authors).

239x111mm (300 x 300 DPI) 


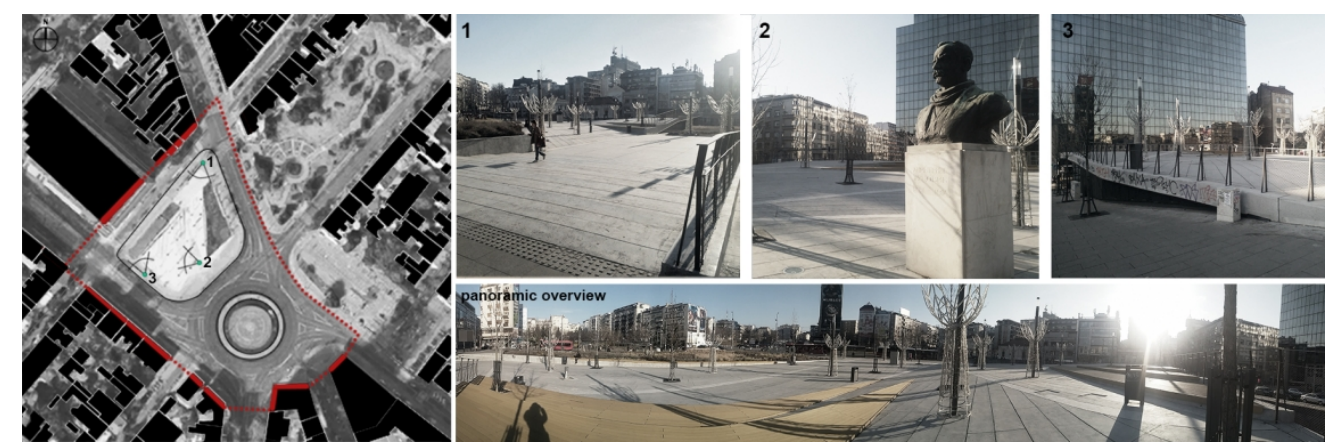

Figure 3 - Overview of Slavija square, its boundaries and surrounding area (Source: Authors). $152 \times 50 \mathrm{~mm}(300 \times 300 \mathrm{DPI})$ 

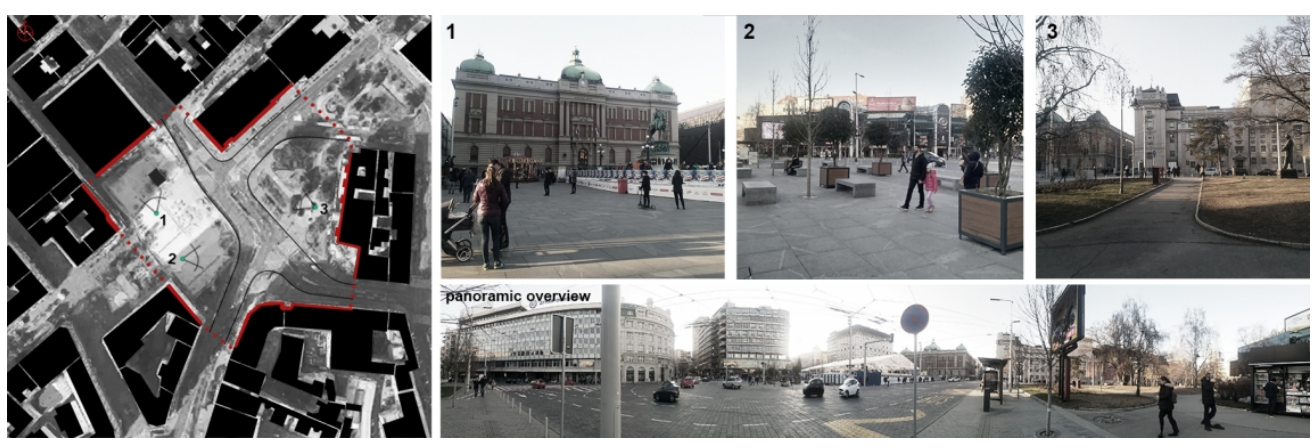

Figure 4 - Overview of Republic square, its boundaries and surrounding area (Source: Authors).

$152 \times 49 \mathrm{~mm}(300 \times 300 \mathrm{DPI})$ 

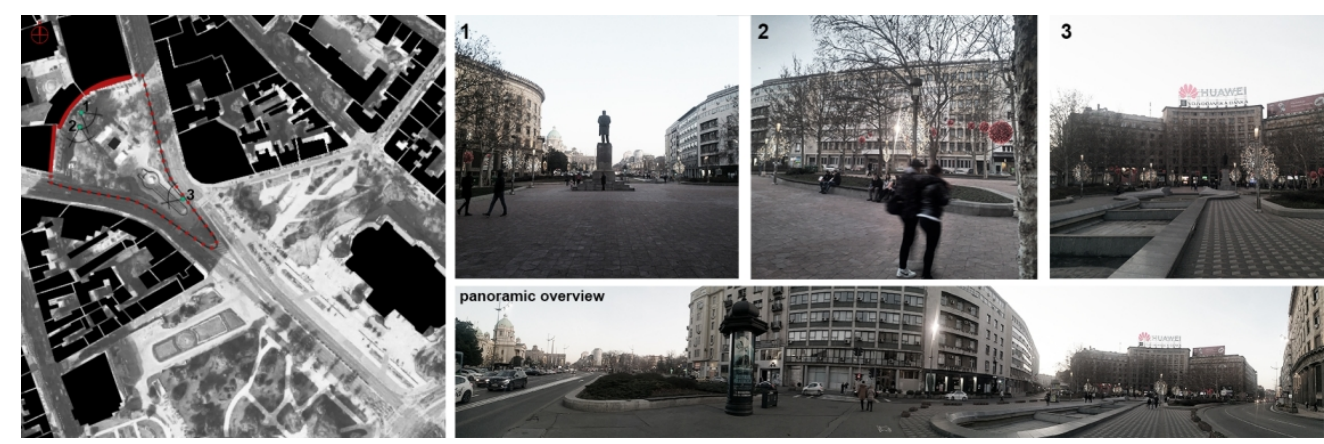

Figure 5 - Overview of Nikola Pašić square, its boundaries and surrounding area (Source: Authors).

$152 \times 49 \mathrm{~mm}(300 \times 300 \mathrm{DPI})$ 


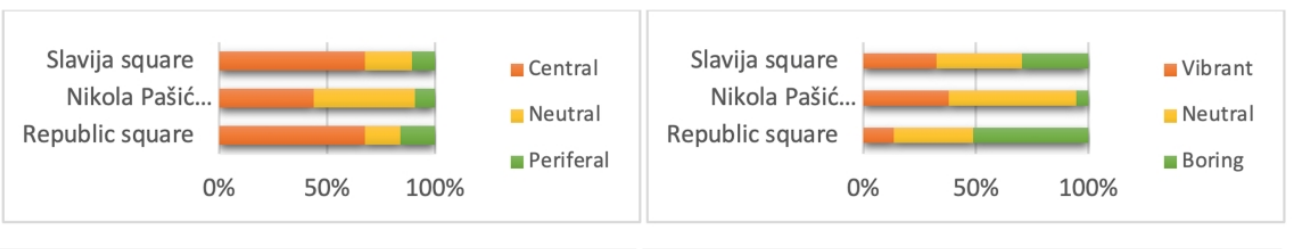

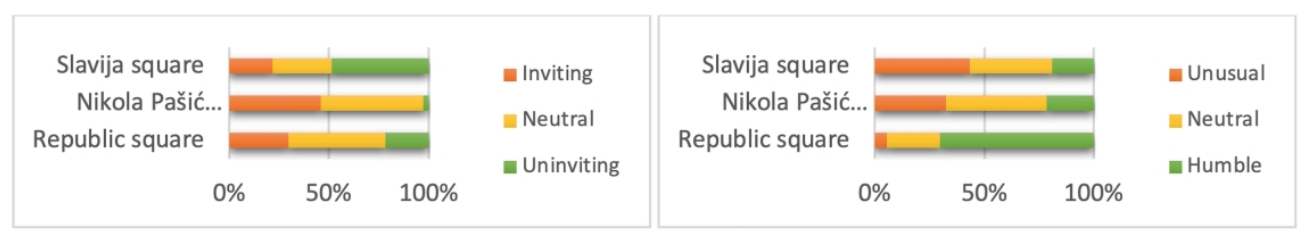

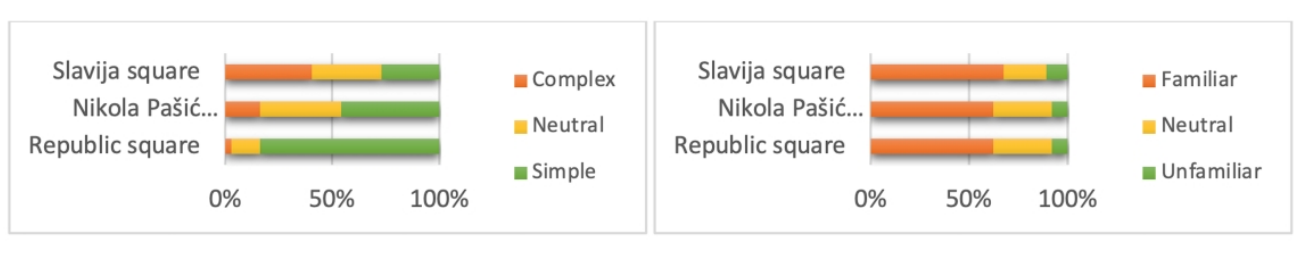

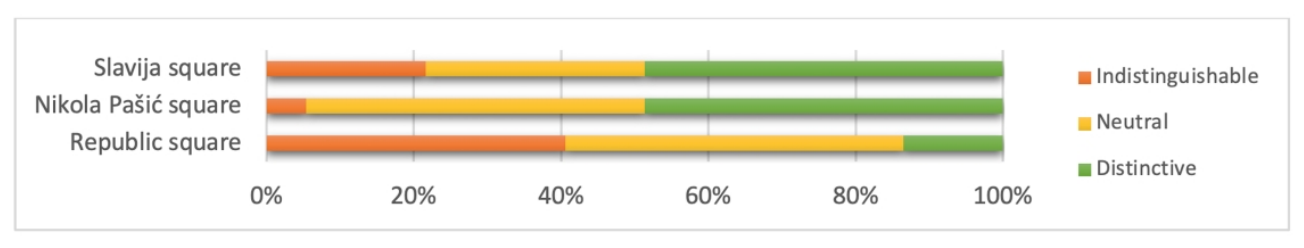

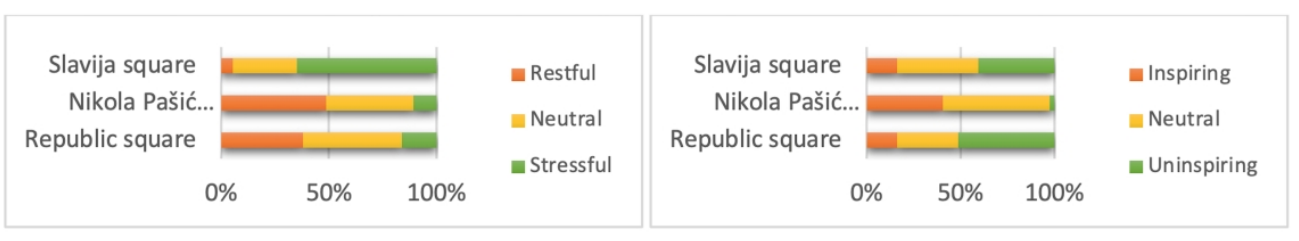

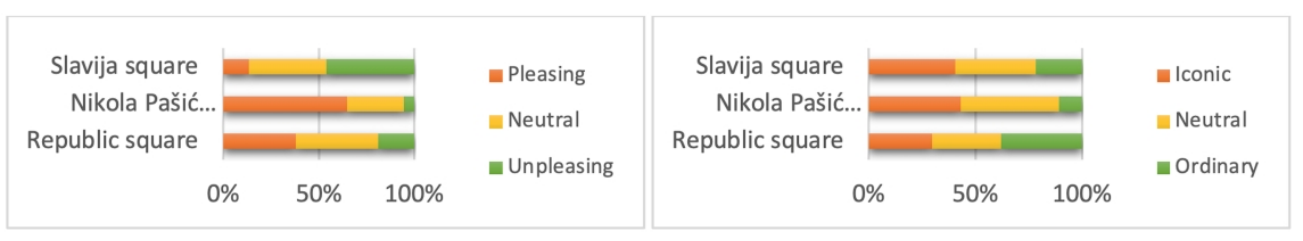

Figure 6 - Key adjectives of the three squares as defined by the users (respondents) through the photographic attitude survey (Source: Authors). 


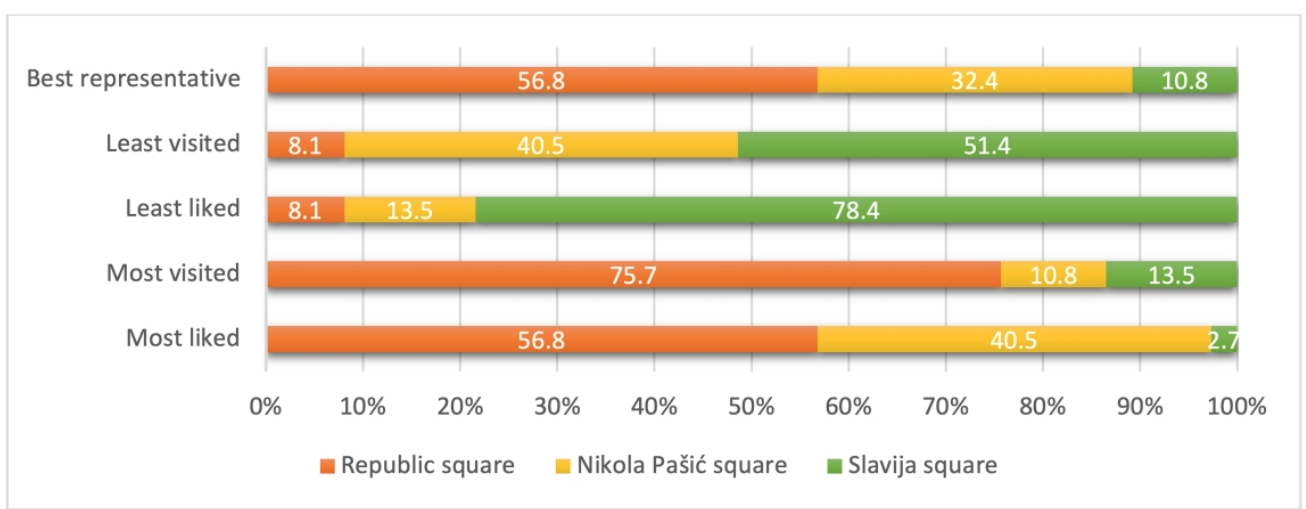

Figure 7 - Users' description of the spaces as they relate to the city and to their experience (Source: Authors). 